\section{Health-and-Environment Indicators in the Context of Sustainable Development}

\author{
Yasmin E. von Schirnding, PhD
}

\author{
"Indicators are a way of seeing the big picture by looking at a small piece of it." \\ Jackson Community Council, quoted in Plan Canada $1999^{1}$
}

\section{ABSTRACT}

This paper gives a broad overview of issues relevant to the development and use of healthand-environment indicators in the broader context of sustainable development. Criteria for the construction of indicators are given, and their key characteristics are highlighted. Selected international indicator initiatives are discussed, as well as the concept and use of core indicators in policy and planning. Finally, an organizational framework for the consideration of health-environment-development linkages is presented, which can be used in the development of health-and-environment indicators in various contexts. This framework is the Driving forces-Pressures-State-Exposures-Health Effects-Actions framework (DPSEEA) of the World Health Organization (WHO). It is a descriptive representation of the way in which various driving forces generate pressures which affect the state of the environment, and ultimately human health through the various exposure pathways by which people come into contact with the environment. Throughout the paper, emphasis is placed on work done within the UN system, in particular that of the $\mathrm{WHO}$, and examples of suites of indicators developed and in use are provided.

\section{RÉSUMÉ}

L'article offre une vue d'ensemble des enjeux relatifs à l'élaboration et l'utilisation $d^{\prime}$ indicateurs de santé et d'environnement dans le contexte plus large du développement durable. L'auteur propose des critères pour la construction d'indicateurs et en souligne les principales caractéristiques. Il traite de certains projets d'indicateurs à l'échelle planétaire ainsi que de la conception et de l'utilisation d'indicateurs de base pour l'élaboration de politiques et la planification. De plus, il présente un cadre organisationnel qui tient compte des liens entre la santé, l'environnement et le développement et qui peut servir à la mise au point d'indicateurs de santé et d'environnement dans divers contextes. Ce cadre de l'Organisation mondiale de la Santé (OMS) s'intitule Forces motrices-Pressions-ÉtatExposition-Effets sur la santé-Actions (DPSEEA en anglais). Il constitue une représentation descriptive de la manière dont les diverses forces motrices exercent des pressions qui touchent l'état de l'environnement puis la santé humaine, vu les diverses voies d'exposition par lesquelles les personnes entrent en contact avec l'environnement. L'auteur insiste sur le travail effectué dans le réseau de l'ONU, notamment dans celui de l'OMS, et fournit des exemples de groupes d'indicateurs mis au point et utilisés.

World Health Organization

Correspondence: World Health Organization, 20 Avenue Appia, Geneva 27, Switzerland 1211 Tel: 4122791 3533, Fax: 4122791 4153,E-mail: vonschirndingy@who.int
Information for decision-making Chapter 40 of the global action plan on sustainable development, Agenda 21, dealing with information for decision-making, states that "in sustainable development, everyone is a user and provider of information in the broad sense." While health, environment and development problems differ in various parts of the world, as do priorities with respect to their management, there is a need in all situations for decisionmakers and the public to have ready access to accurate information on health hazards associated with the linkages between development and the environment.

Information is needed to monitor and assess trends, identify and prioritize problems, develop and evaluate policies and plans, guide research and development, set standards and guidelines, monitor progress and inform the public. It is important that these data be conveyed in a readily comprehensible way, but with due regard to the complexities and uncertainties inherent in the data.

\section{Role of indicators}

Indicators can play an important role in turning data into relevant information for decision-makers and the public. They can help to simplify a complex array of information with respect to the health-environmentdevelopment nexus and in this way provide a "synthesis" view of existing conditions and trends. They have become well established and widely used in many different fields and can be used at the global, regional, national, local or neighbourhood level, as well as at the sectoral level. ${ }^{3}$ (see Figure 1)

Briggs et al. ${ }^{4}$ have defined an environmental health indicator as: "An expression of the link between environment and health, targeted at an issue of specific policy or management concern and presented in a form which facilitates interpretation for effective decision-making." Embodied in this definition is the concept of a linkage between a factor in the environment and a health outcome.

Examples of indicators are numerous and include such measurements as GDP (Gross Domestic Product) as a way of assessing aspects of economic development in a country, the infant mortality rate (IMR) as an indicator of the health status of a community, or the rise in ambient temperatures, worldwide, as an indicator of climate change. 


\section{Criteria for indicators}

To be useful, indicators should be userdriven, and not just technically relevant or relevant to the providers of data. The actual choice of indicators depends on factors such as the purpose for which they are to be used, and the target audience. Many organizations have attempted to define criteria for the construction and selection of indicators and have included various factors such as transparency, scientific validity, robustness, sensitivity and the extent to which they are linkable. ${ }^{5}$ Further, they could be assessed according to whether they are relevant to the issue they are intended to describe, whether they relate to changes in policy and practice, or whether or not they are resonant with their intended audience. ${ }^{5}$

Criteria which could be used in the development of indicators are given in Figure 2 . The applicability of the criteria will depend on the indicator in question, and the purpose of the indicator to be used. However, no single set of criteria will be applicable to all indicators as each situation will have its own priorities for data collection and analysis.

\section{NATURE AND CHARACTERISTICS OF INDICATORS}

Indicators may be specific, or may be composites which condense a wide range of information on different (but related) phenomena into a single measure or index. The construction of composite indicators is challenging, and demands high levels of statistical and measurement competence in weighting and combining various variables. Composite indicators may be difficult to test or verify as they may not relate to specific, measurable conditions. Composite indices can nevertheless be useful in summarizing data and information for decisionmakers. For instance, in the field of health, the "DALY" is an example of a composite measure of the burden of disease based on the concept of disability-adjusted life years, which combines the years of healthy life lost due to premature death, disability or disease. $^{6}$

At all levels (global, regional, local), indicators that describe the overall state (quality) of the environment, and that highlight factors influencing environmental quality, as well as potential impacts on human health,

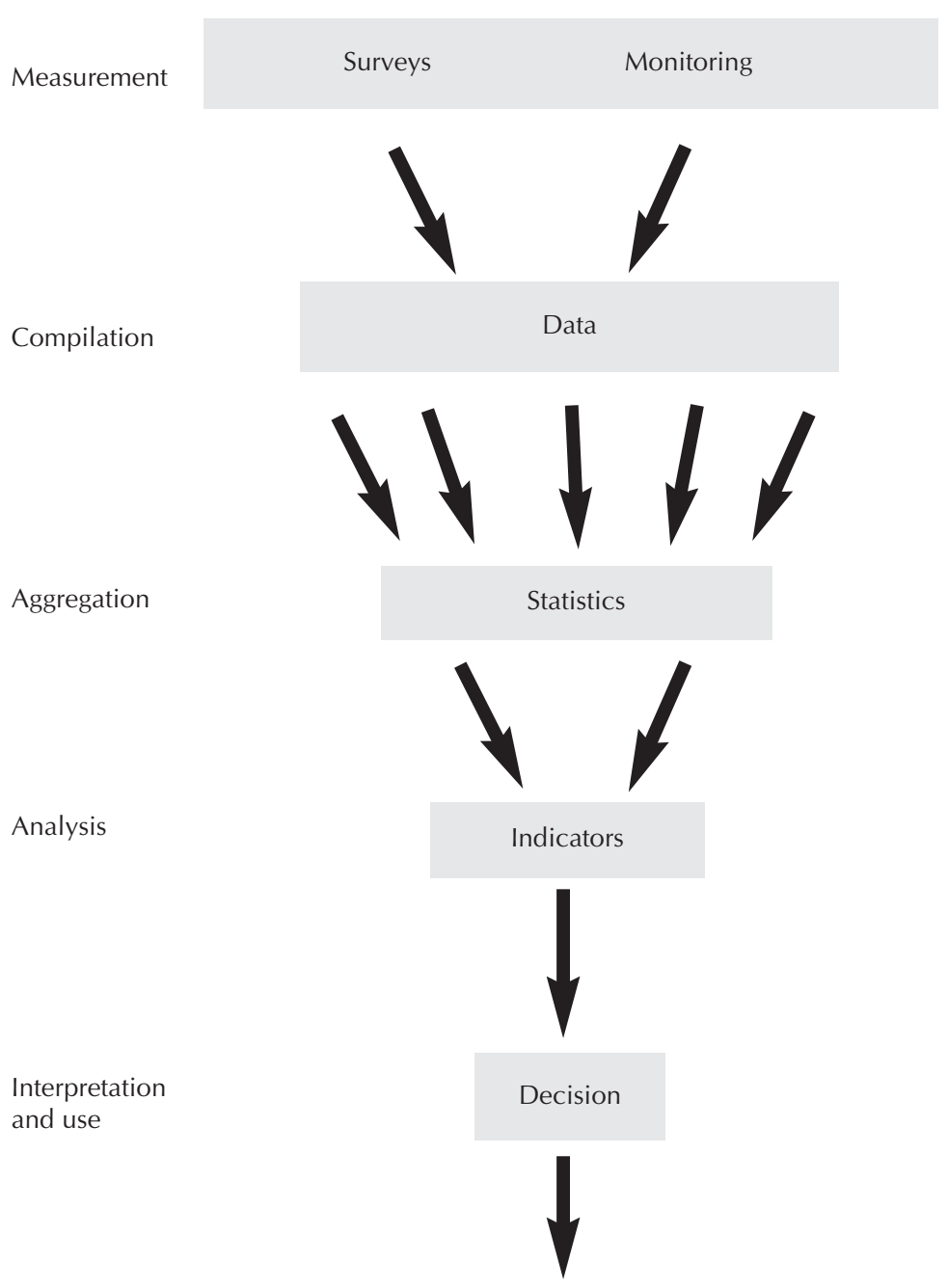

Figure 1. Hierarchy of information to indicators and their use in decision-making.

Of general relevance

- related to a specific question or issue of concern

- health-related and linked to environment/development factors

- sensitive to changes in the conditions of interest

- provide early warning of pending changes.

Scientifically sound

- unbiased and representative of the conditions of concern

- scientifically credible, reliable and valid

- based on best available data of acceptable quality

- robust and unaffected by minor changes in methodology/scale used for their construction

- consistent and comparable over time and space.

Applicable to users

- have relevance to policy and management needs

- based on data which are available or can be collected/monitored with a reasonable financial/time resource input

- easily understood and usable by potential users

- acceptable to stakeholders.

Source : Modified and adapted from Briggs et al. ${ }^{4}$

\section{Figure 2. Criteria for indicators}

can be useful. They can provide an overview, or snapshot of a situation, or a profile of environment-and-health conditions, thereby identifying trends. In this regard, the indicator framework described in the last section of this article has application.
Indicators that describe the various policy responses taken to address problems can be of value. In developing countries in particular, where the data base necessary to construct indicators may be limited, but the problems (and solutions) are well known, it 
may be more appropriate to focus on the development of response, or action indicators, than on indicators relying on data from extensive monitoring programs. ${ }^{5}$ Performance indicators, which measure whether agreed targets and goals have been met, may be very useful in these cases.

\section{INTERNATIONAL INDICATOR} INITIATIVES

\section{Sustainable development indicators}

Many intergovernmental and nongovernmental organizations and countries have developed indicators of sustainable development, supported by the United Nations. In the early-to-mid 1990s, organizations such as the OECD, ${ }^{7} \mathrm{UNEP} / \mathrm{RIVM},{ }^{8}$ the World Resources Institute (WRI), ${ }^{9}$ the World Bank, ${ }^{10}$ SCOPE $^{11}$ and others became centrally involved in the development of indicators to monitor environmental trends. ${ }^{3}$

To date, around 130 indicators of sustainable development have been compiled by the Commission on Sustainable Development. ${ }^{12}$ These indicators are currently being tested at the national level by countries throughout the world and, based on analysis of the test results and review of developments in other international indicator sets, a core set of indicators for sustainable development (and related methodologies) will be developed as a tool to support national-level decisionmaking in the future. The core set is based on the policy priorities of Agenda 21 and was presented for endorsement to the Commission on Sustainable Development in August-September 2002.

\section{Housing and urban indicators}

Indicators indirectly of relevance to health also include those developed by the UNCHS on housing and urban areas, ${ }^{13}$ which constitute a monitoring package for cities and the shelter sector. Key indicators for this work were endorsed by the Commission on Human Settlements in May 1995, and constituted a set of indicators collected by countries as part of their preparation for HABITAT II. ${ }^{13}$ The indicators cover the areas of socioeconomic development, infrastructure, transport, environmental management, local government, housing affordability, availability and provision, as well as some general related background topics. ${ }^{13}$

\section{Social indicators of development}

Social indicators of development have been compiled by the World Bank ${ }^{14}$ to assess reductions in poverty. They include indicators of priorities, supplementary indicators of access to basic services and social safety nets, and indicators of human resources, natural resources, socioeconomic expenditure and investment in human capital.

\section{Health indicators}

WHO headquarters and regional offices have developed indicators (and targets) to assess its "Health-for-All" (HFA) policy. The purpose of the HFA indicators has been to guide member states in the evaluation of their national strategies for HFA, and to follow up on the implementation of the Global Strategy. HFA indicators previously developed dealt with trends in policy and socioeconomic development, health and the environment, health resources, health systems, health services and health status. ${ }^{15}$ Further, global indicators are used for reporting purposes in the World Health Report of WHO and are used extensively in various regions of the WHO.

WHO has also developed programme indicators to monitor the health of infants and young children, women and the health of the general population, and to assess the status of specific situations (e.g., vitamin A deficiencies). ${ }^{16}$

Much work has also been done on indicators for environmental health. ${ }^{4,17}$ No uniform set of EHIs has been recommended by WHO, however suites of indicators which can be selected from for various purposes have been compiled, ${ }^{18}$ and methodology sheets for construction of selected indicators have been updated. (See Table I: Environmental Health Indicators) (For a comprehensive listing of example indicator sets, see http://ottserver1. ottawa.ijc.org/hptf/).

Baseline indicators have been developed by the WHO European Healthy Cities project, covering health, demography, health services, the environment and socioeconomic status. ${ }^{19}$ The indicators were formally adopted by participating cities in 1990, and information has been collected on the 53 agreed indicators from cities for the period 1992 to 1994. Further, WHO has published a set of guiding principles to evaluate food safety programmes as well. ${ }^{20}$

\section{CORE INDICATORS}

Despite the existing arguments against a set of "core" indicators that could be used on a global scale to examine overall trends in environment and health conditions, most countries face the reality of having to deal with certain problems that are of universal significance. These might include air quality, access to potable water and sanitation, food safety, waste disposal, or toxic substances for example. While the specific dimensions of these problems will differ within and between countries, sets of universally applicable indicators could be valuable in improving shared knowledge on these and other issues. Further, common sets of indicators enable aggregation at various levels - local, country, regional, and global; provide momentum to countries in achieving uniform and rigorous standards; and provide tracking tools to monitor the success of international treaties.

It is argued that establishing agreement on a common set of indicators will significantly lessen the data-reporting burden on countries. Where user needs are similar, indicators should be harmonized. Efforts should be coordinated between government departments, agencies, NGOs, civil society and the donor community and where possible, existing data should be drawn upon, paying due recognition to the limitations of the data.

The common country assessment (CCA) indicator framework, developed by the United Nations Development Group (UNDG) as an indicator framework is currently being used by UN funds and programmes in over 100 countries.

Both the UN Statistics Division and UNDG are working with a selected number of countries to assess a) to what extent the national statistics system is involved in the CCA indicator effort and what the impacts are of the CCA indicator requirements on the national statistics system; b) which indicators are being used; c) what the data gaps are; d) how the UN Development Assistance Framework (UNDAF)-CCA indicator process is related to other policy processes (for example, IMF/World Bank Poverty Reduction Strategies for countries qualifying for enhanced debt relief); and e) what targeted programmes are being proposed to address the lack of data or data quality. ${ }^{21}$ 
TABLE I

Summary List of Environmental Health Indicators

Issue

Socio-demographic context

Air pollution

Sanitation

Shelter

Access to safe drinking water

Vector-borne disease

Hazardous/Toxic substances

Food safety

\section{Theme/Topic}

Poverty

Population density

Population growth

Age structure

Urbanization

Infant mortality

Life expectancy

Outdoor air pollution

Indoor air pollution

Respiratory illness

Air quality management

Air quality management

Excreta disposal

Diarrhoea

Informal settlements

Unsafe housing

Home accidents Urban planning

Water quality/supply

Water quality/supply

Diarrhoea

Diarrhoea

Water-borne diseases

Water quality monitoring Intensity of water quality

Population at risk

Vector-borne disease mortality

Vector control

Waste collection

Waste disposal

Waste management

Blood lead

Chemical poisonings Contaminated land

Food-borne diseases Diarrhoea

Diarrhoea children

Monitoring of food safety Monitoring of chemical

Radiation exposure

UV exposure hazards in food

\section{Indicator}

Poverty

ensity

population grow

Rate of urbanization

Infant mortality rate

Life expectancy

Ambient concentrations of air pollutants in urban areas

Sources of indoor air pollution

Childhood morbidity due to acute respiratory illness management

Availability of lead-free gasoline

Diarrhoea morbidity in children

Percentage of population living in informal settlements

Percentage of population living in unsafe housing

Urban planning and

building regulations

Access to safe and reliable supplies of drinking water

Connections to piped water supply

Diarrhoea morbidity in

children

Population at risk from vector-borne diseases

Mortality due to vectorborne diseases

Adequacy of vector contro and management systems

Municipal waste collection

Municipal waste disposal

Hazardous waste policies

Blood-lead level in childre

Mortality due to poisoning

Contaminated land

management

Food-borne illness

Diarrhoea morbidity in

children

Cumulative radiation dose

UV light index

\section{Example Definition}

Human poverty index (compound index) Population density

Annual net rate of population growth

Percentage of people aged

$<16$ years or $\geq 65$ years

Annual net rate of change in the proportion

of people living in urban areas

Annual death rate of infants under

one year of age

Number of years a newborn baby is expected Effect

to live, given the prevailing mortality rate

Mean annual concentrations of ozone,

$\mathrm{CO}$ particulates ( $\left.\mathrm{PM}_{10}, \mathrm{PM}_{2.5}, \mathrm{SPM}\right), \mathrm{SO}_{2}$,

$\mathrm{NO}_{2}, \mathrm{O}_{3}$ and lead in the outdoor air in

urbann areas

Percentage of households using coal, wood

or kerosene as the main source of heating

and cooking fuel

Annual mortality rate due to acute respiratory Effect

infections in children under five years of age

Capability to implement air quality

management

Consumption of lead-free gasoline as a

percentage of total gasoline consumption

Proportion of the population with access

to adequate excreta disposal facilities

Incidence of diarrhoea morbidity in

children under five years of age

Percentage of the population living in informal settlements

Action

Action

Exposure

Effect

Exposure

Percentage of the population living in unsafe, Effect unhealthy or hazardous housing

Incidence of accidents in the hom

Scope and extent of building and planning

regulations for housing

Percentage of the population with access to an adequate amount of safe drinking water

in the dwelling or within a convenient

distance from the dwelling

Percentage of households receiving piped

water to the home

Incidence of diarrhoea morbidity in children

under five years of age

Diarrhoea mortality rate in children under

five years of age

Incidence of outbreaks of water-borne

diseases

Density of water quality monitoring network

Number of people living in areas infected by disease vectors

Mortality rate due to vector-borne diseases

Percentage of the at-risk population covered by effective vector control and management systems, by disease type

Percentage of population served by regular waste collection services

Mass of solid waste disposed of by municipal Action waste management services

Effectiveness of hazardous waste policies and regulations

levels $>10$ ug/dl

Mortality rate due to poisoning

Scope and rigour of contaminated

land management

dillness

Incidence of diarrhoea morbidity in children under five years of age

Diarrhoea mortality rate in children under

five years of age

Proportion of potentially hazardous

chemicals monitored in food

Percentage of the population receiving an effective radiation dose in excess of $5 \mathrm{mS} / \mathrm{yr}$ UV light index
Effect

Action

Exposure/

Action

Exposure/

Action

Effect

Effect

Effect

Action

Exposure

Action

Action

Action

Action

Exposure

Effect

Action

Effect

Effect

Effect

Action

Exposure

Exposure 
TABLE I, continued

Summary List of Environmental Health Indicators

\begin{tabular}{|c|c|c|c|c|}
\hline Issue & Theme/Topic & Indicator & Example Definition & DPSEEA \\
\hline \multirow[t]{3}{*}{ Non-occupational health risks } & Motor vehicle accidents & $\begin{array}{l}\text { Mortality from motor } \\
\text { vehicle accidents }\end{array}$ & Death rate due to road accidents & Effect \\
\hline & Non-occupational injury & Injuries to children & $\begin{array}{l}\text { Incidence of physical injury to children less } \\
\text { than } 5 \text { years of age }\end{array}$ & Effect \\
\hline & Poisoning & $\begin{array}{l}\text { Incidence of poisonings } \\
\text { of young children }\end{array}$ & $\begin{array}{l}\text { Number of reported poisonings per year in } \\
\text { children under } 5 \text { years of age }\end{array}$ & Effect \\
\hline \multirow[t]{3}{*}{ Occupational health risks } & Occupational hazards & $\begin{array}{l}\text { Exposure to unsafe } \\
\text { workplaces }\end{array}$ & $\begin{array}{l}\text { Percentage of workers exposed to unsafe, } \\
\text { unhealthy or hazardous working conditions }\end{array}$ & Exposure \\
\hline & Occupational morbidity & $\begin{array}{l}\text { Morbidity due to } \\
\text { occupational health hazards }\end{array}$ & Incidence of occupational injury & Effect \\
\hline & Occupational mortality & $\begin{array}{l}\text { Mortality from occupational } \\
\text { health hazards }\end{array}$ & Incidence of occupational mortality & Effect \\
\hline
\end{tabular}

Source: WHO $1999^{25}$

TABLE II

Health and Environment Issues of Significance at Local, National and Global Levels

\begin{tabular}{lll} 
Local & National & Global \\
Dust & Hazardous waste & Climate change \\
Noise & Toxic chemicals & Transboundary pollution \\
Solid waste & Food safety & Ozone depletion \\
Water and sanitation & Ambient air pollution & Acid deposition \\
Pests & (major industrial/mobile sources) & Marine pollution \\
\hline
\end{tabular}

\section{TABLE III \\ Global Reports}

\section{Report Title}

Global environment outlook

Human development report

State of the world's children

United Nations statistical yearbook

Vital signs

State of the world

State of world rural poverty

World development report

World health report

World health statistics annual

World resources report

While standard, internationally agreed upon sets of indicators are valuable for various reasons, nations may require other specific indicators to enable them to develop and evaluate national policies and plans. Therefore, any core set of indicators will have to be augmented in view of the particular national, regional and local policy concerns.

The roles and responsibilities with respect to various environment and health management functions at different tiers of government, the degree of decentralization of powers and functions, and other factors such as data availability and quality, will influence the extent to which it makes sense to examine data at different levels for international comparison purposes. Regardless of at what level the data are aggregated and examined, however, most information will normally need to be collected in the first instance, at the lowest level of resolution as is practicable and feasible.

\author{
Organization \\ UNEP, Nairobi \\ UNDP, New York \\ UNICEF, New York \\ UN, New York \\ Worldwatch Institute Washington \\ Worldwatch Institute Washington \\ IFAD, Rome \\ World Bank, Washington \\ WHO, Geneva \\ WHO, Geneva \\ World Resources Institute Washington
}

The issues in Table II could have particular relevance at the global, national and local levels respectively, although it should be recognized that there are no rigid boundaries and the situation will vary from setting to setting, depending on the sources and the factors influencing their control (for example, local issues impact on global issues, and vice versa). At the national level, the setting of policies and standards may be fundamental, while at the local level, service delivery and implementation of policies is normally of key importance. Many issues require management over different tiers of government.

Table III provides examples of regularly published global reports containing detailed health and/or environment information.

The quality and quantity of health information has been improving over the years, with advances in health information systems and in health reporting. There are several international information sources available on environmental health effects, such as the Environmental Health Criteria (WHO, UNEP and ILO), the International Register of Potentially Toxic Chemicals, monographs on carcinogenicity of chemical substances (International Agency for Research on Cancer - IARC), and various WHO guideline documents such as those on drinking water quality and air quality.

Obtaining relevant data at the country level remains a significant problem and more so in poorer countries. Nevertheless most countries have some sort of health information system and problems in data coverage and data quality occur in almost all countries, to a greater or lesser degree.

\section{LINKAGES AND FRAMEWORKS}

It is important for decision-makers not only to obtain better data on, but also to obtain an enhanced understanding of, the linkages among the factors in the environmentdevelopment processes affecting human health. Several indicator frameworks for presenting the various linkages among factors influencing health in the context of environment and development have been developed, which are all adaptations of the "Pressure-State-Response" (PSR) framework developed by $\mathrm{OECD}^{7}$ (in turn based on earlier work done by the Canadian government) (See Figure 3).

The PSR framework for the environment has been criticized for being linear and uni-directional. One example proposed to address this linearity is a model developed by the Commonwealth of Australia, indicating the feedback loops in circular fashion. $^{22}$ (See Figure 4)

Other adaptations to the PSR framework have made provision for the broader 
driving forces and pressures on the environment, as well as for the resulting impacts. A framework referred to as the PSIR framework (Pressure-State-ImpactResponse) has been developed which makes provision for impacts such as those on human health, ecosystems, or economic and social systems. ${ }^{23}$ (See Figure 5)

Both the exposures and resulting human health effects have been taken into account in a further adaptation of the framework for health purposes, referred to as the "DPSEEA" framework, which represents Driving forces, Pressures, State, Exposures, Health effects, and Actions. ${ }^{4,17,18}$ It is a descriptive representation of the way in which various driving forces generate pressures which affect the state of the environment, and, ultimately, human health, through the various exposure pathways by which people come into contact with the environment.

People may become directly "exposed" to potential hazards in the environment when coming into direct contact with these media through for example breathing, drinking or eating. A variety of health effects may subsequently occur, ranging from minor, subclinical effects (i.e., effects that may not yet have manifested in overt symptoms) through to illness and sometimes death, depending on the intrinsic harmfulness of the pollutant, the severity and intensity of exposure and the susceptibility of the individual exposed (for example, the elderly, the young and the sick may often be more susceptible than others).

While the DPSEEA framework, like the original PSR framework, represents the various components in a linear fashion to more clearly articulate the connections among factors influencing health and the environment, in reality the situation is much more complex, with various interactions occurring at different levels among various components. The different components of the DPSEEA framework are shown in Figure 6. The framework can be applied to information gathering and indicator development at the national, sectoral, or indeed at the community or neighbourhood level. ${ }^{24,25}$ (See Figure 6)

\section{SUMMARY}

This paper has attempted to give a broad view of issues relevant to the development and use of health-and-environment indica-

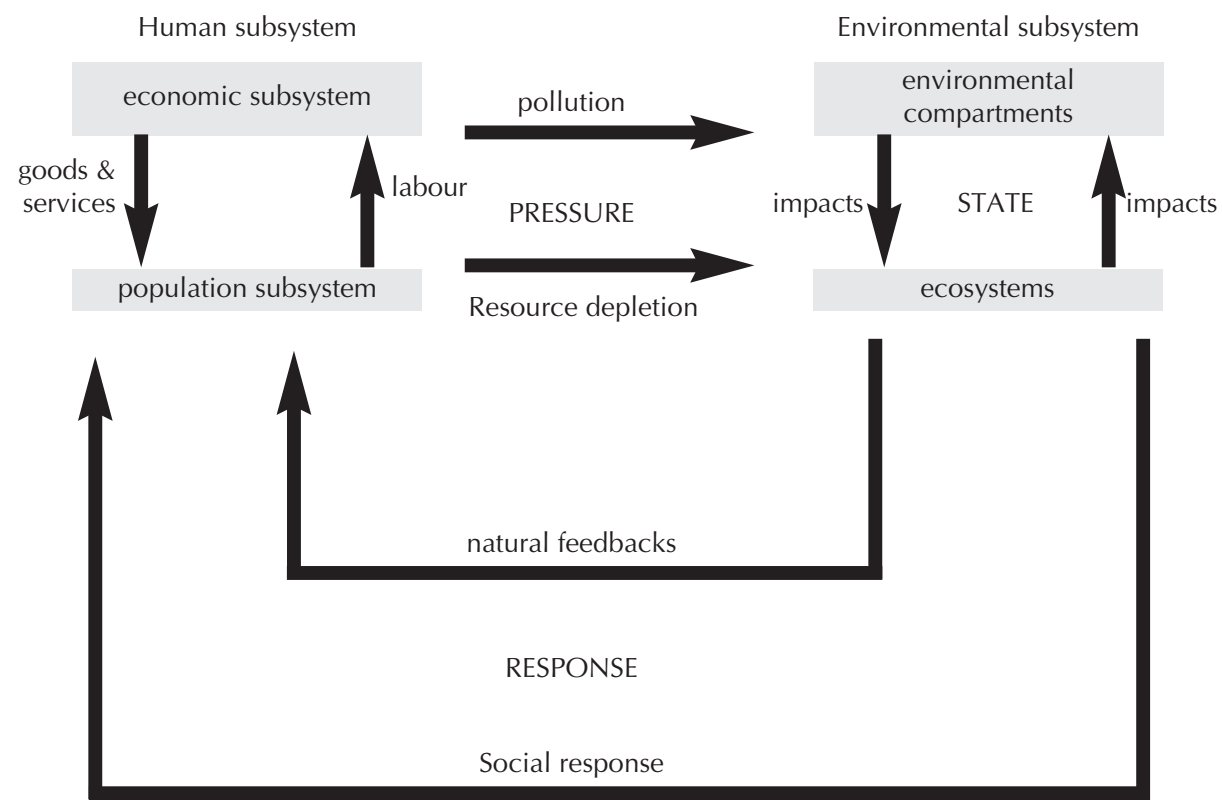

Human system feedback

Figure 3. OECD Pressure-State-Response framework for indicators.

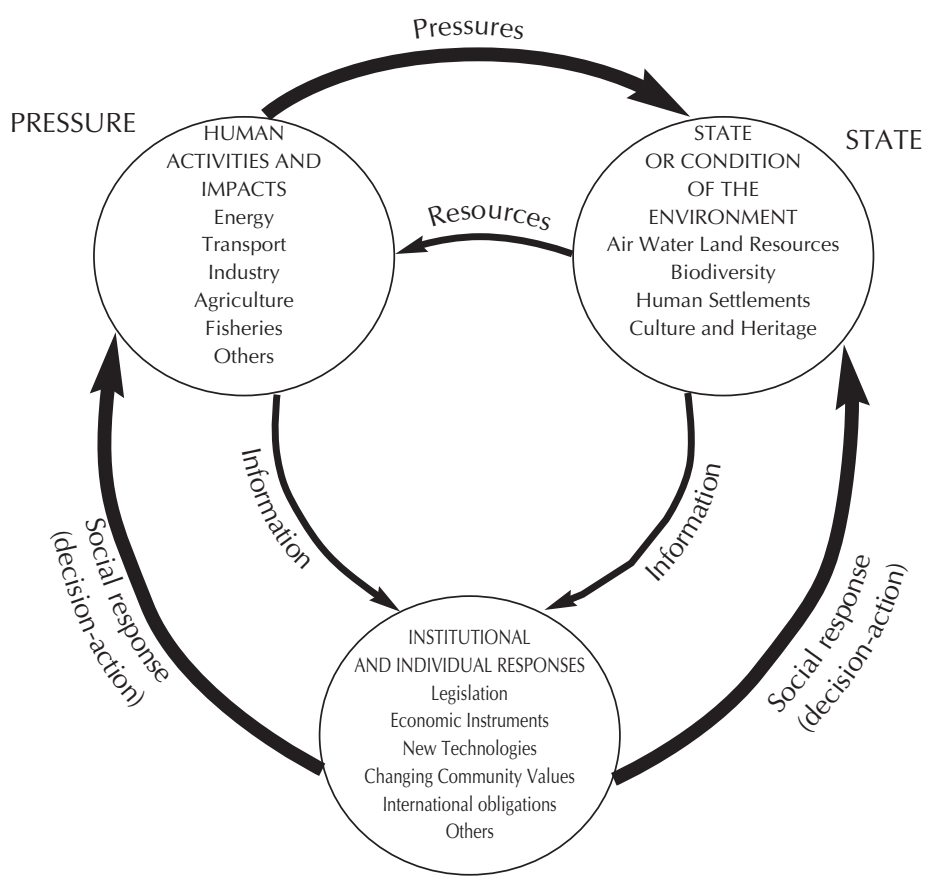

Figure 4. Commonwealth of Australia Pressure-State-Response framework for indicators.

tors. Criteria for indicator development, national and international indicator initiatives, and the concept of core indicators have been presented and discussed. Finally, frameworks for the consideration of health-environment-development linkages have been presented, which may be useful for the development of health-andenvironment indicators in various contexts throughout the world.

\section{REFERENCES}

1. Plan Canada. Sustainable community indicators programme. 1999;39(5).

2. United Nations. Agenda 21: Programme of Action for Sustainable Development. Rio Declaration on Environment and Development. Rio de Janeiro, Brazil, 1993.

3. Hammond A, Adriaanse A, Rodenburg E, Bryant D, Woodward R. Environmental indicators: A systematic approach to measuring and reporting on environmental policy performance in the context of sustainable development. Washington, DC: World Resources Institute, 1995. 


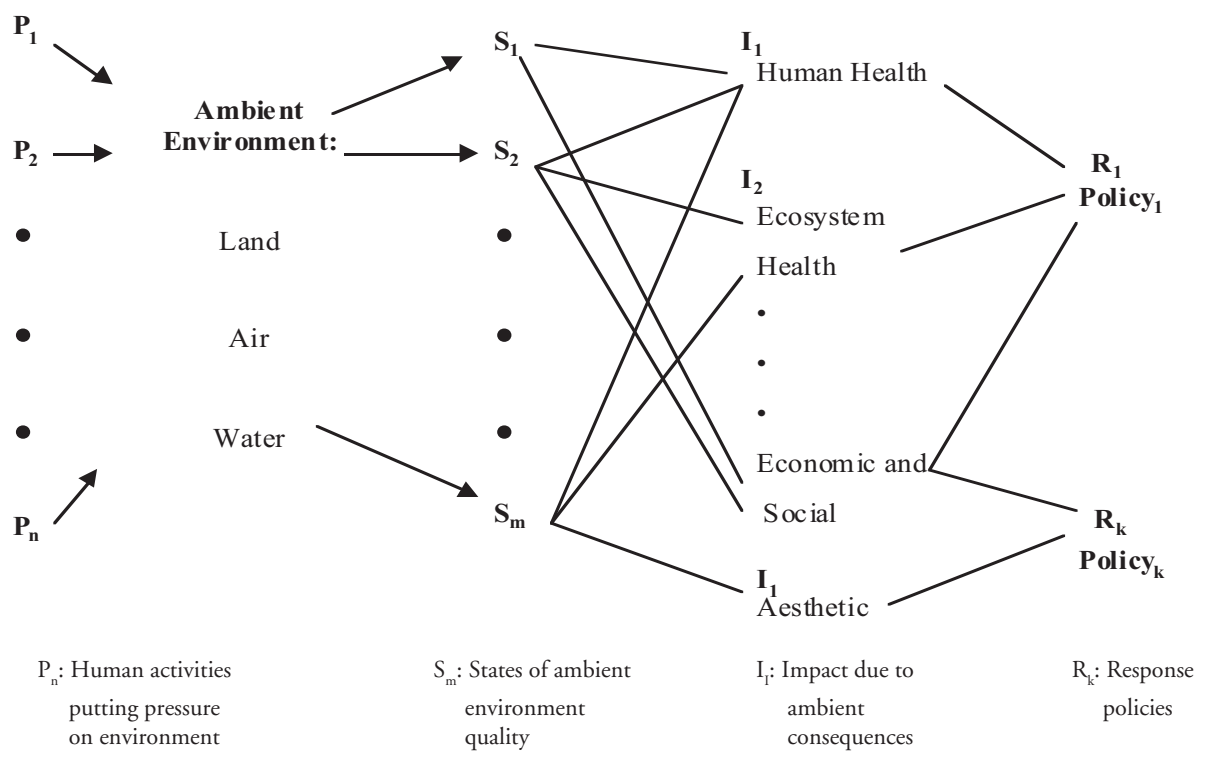

Figure 5. The Pressure-State-Impact-Response framework for indicators.

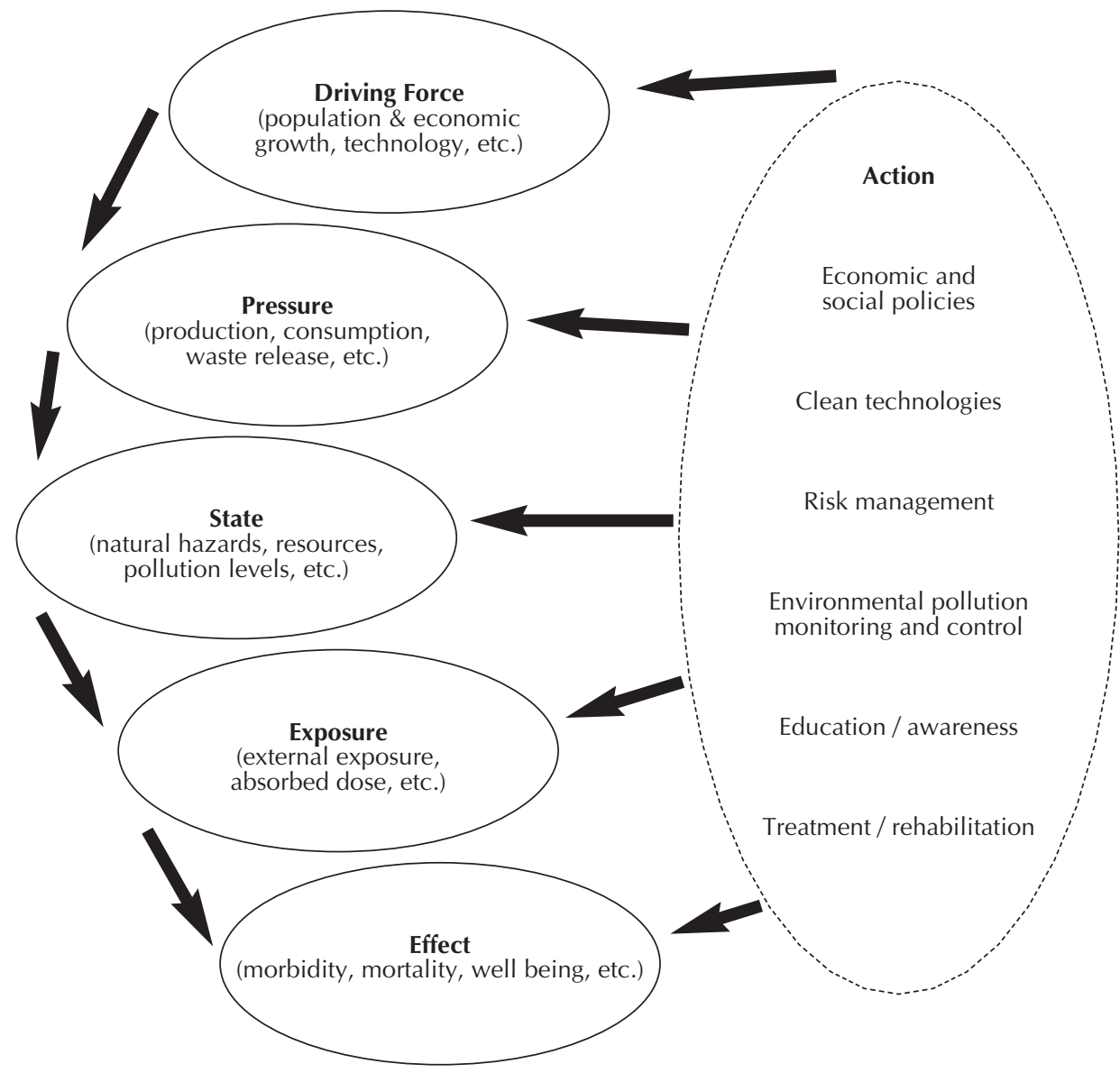

Figure 6. The Driving Forces, Pressure, State, Exposure, Effect, Action (DPSEEA) model of $\mathrm{WHO}^{25}$

4. Briggs D, Corvalan C, Nurminen M. Linkage methods for environment and health analysis. UNEP/US EPA/WHO. Geneva, Switzerland, 1996.

5. Peterson P. Indicators of sustainable development in industrialising countries. Lestari Monographs,
Penerbit University Kebangsaan, Bangi, Malaysia, 1997.

6. Murray C, Lopez A. The global burden of disease: A comprehensive assessment of mortality and disability from diseases, injuries and risk fac- tors in 1990 and projected to 2020. Harvard University Press, 1996

7. OECD. OECD core set of indicators for environmental performance reviews. Environmental Monograph 83, OECD, Paris, France, 1993.

8. UNEP/RIVM. An overview of environmental indicators: State of the art and perspectives. UNEP/EATR.94-01; RIVM/402001001, 1994.

9. World Resources Institute. Environmental indicators: A systematic approach to measuring and reporting on environmental policy in the context of sustainable development. New York, NY: WRI, 1995.

10. World Bank. Monitoring environmental progress: A report of work in progress. Washington, DC: The World Bank, 1994.

11. SCOPE. Environmental indicators: A systematic approach to measuring and reporting on the environment in the context of sustainable development. Paper presented at the workshop on Indicators of Sustainable Development for Decision-making. Ghent, January 9-11, 1995

12. United Nations. Indicators of sustainable development: Framework and methodologies. New York, NY: UN, 1996.

13. UNCHS. Monitoring human settlements: Abridged survey. Nairobi, Kenya, 1995.

14. World Bank. Social Indicators of Development. Baltimore and London: Johns Hopkins University Press, 1996.

15. WHO. Health-for-All in the 21 st century Geneva: WHO, 1998.

16. WHO. Indicators for Assessing Vitamin A Deficiency and Their Application in Monitoring and Evaluating Intervention Programmes. Geneva, Switzerland: WHO, 1996.

17. WHO. Health and environment analysis and indicators for decision-making. World Health Statistics Quarterly 1995;48(2).

18. von Schirnding Y. Health and environment in sustainable development planning: The role of indicators. Paper prepared for World Summit on Sustainable Development. Geneva: WHO, 2002.

19. WHO. Catalogue of Health Indicators: A Selection of Important Health Indicators Recommended by WHO Programmes. Geneva: WHO, 1996.

20. WHO. Evaluation of programmes to ensure food safety. Geneva: WHO, 1989.

21. United Nations. Progress Report on Basic Indicators for the Integrated and Coordinated Implementation of and Follow-up to Major UN Conferences and Summits at all Levels. E/2000/60 2000.

22. Commonwealth of Australia. State of the environment reporting: Framework for Australia. Department of the Environment, Sport and Territories, Commonwealth of Australia, Canberra ACT, 1994.

23. Harvard University. Environmental indicators. Report No TA 5542-Reg, Asian Development Bank/Govt of Norway, Environmental Systems Programme, 1996.

24. WHO. Health and Environment in Sustainable Development. Geneva: WHO, 1997.

25. WHO. Environmental Health Indicators: Framework and Methodologies. Geneva: WHO, 1999. 